7) Ockendon, J. R. and W. R. Hodgkins (Ed.): "Moving Boundary Problems in Heat Flow and Diffusion", Claren-

Literature Cited

1) Bellman, R., E. S. Lee and K. M. Wang: Chem. Eng. Sci., 32, 1051 (1977).

2) Bischoff, K. B.: ibid., 18711 (1963).

3) idem: ibid., 20, 783 (1965).

4) Boley, B. A.: J. Math. Phys., 40, 300 (1961).

5) Bowen, J. R.: Chem. Eng. Sci., 20, 712 (1965).

6) Gupta, S. C. and A. K. Lahiri: Int. J. Eng. Sci., 7, 401 (1979). don Press, Oxford (1975).

8) Portnov, I. G.: Soviet Phy. Dokl., 7, 186 (1962).

9) Taniguchi, S., M. Ohmi and M. Yamada: Trans. of Iron and Steel Inst. Japan, 14, 214 (1974).

10) Van Der Pol, B, and H. Bremmer: "Operational Calculus Based on the Two-sided Laplace Integral", Cambridge (1955)

11) Yoshida, K., D. Kunii and F. Shimizu: J. Chem. Eng. Japan, 8, 417 (1975).

\title{
PHOTOCHEMICAL KINETICS IN INFRARED LASER SEPARATION OF BORON ISOTOPES
}

\author{
KaZUo TAKEUCHI, OSAMU KURIHARA aNd RyoHeI NAKANE \\ The Institute of Physical and Chemical Research, Wako, Saitama 35I
}

\section{Introduction}

Since the invention of lasers, their extremely high beam intensity and monochromaticity have been successfully applied to isotope separation ${ }^{5,6}$. When the absorption cross-sections of this monochromatic light source are considerably different for two different isotope compounds (in the most desirable case, one of them is null), monochromatic light in UV, visible and IR regions can excite only one of them electronically or vibrationally. And when dissociation or bi-molecular reaction follows the excitation, the molecule containing a particular isotope can be converted into other substances which can be easily separated from the unreacted compound containing a different isotope, using conventional separation techniques.

When the pulsed IR laser has intensity in the order of $\mathrm{MW} / \mathrm{cm}^{2}$, polyatomic molecules tend to be highly vibrationally excited, absorbing more than one photon. The excited molecules either react with the second gas, called the acceptor, or dissociate into radicals. For the second case, there are two possibilities. Molecules such as $\mathrm{SF}_{6}, \mathrm{CCl}_{4}$ and $\mathrm{CCl}_{2} \mathrm{~F}_{2}$ tend to form stable final products, while molecules such as $\mathrm{BCl}_{3}$ and $\mathrm{SiF}_{4}$ do not, requiring the acceptor for isotope enrichment.

Today, it is well known that such infrared laser isotope separation has many advantages over that in UV or visible region ${ }^{8}$ for such practical applications as uranium enrichment and deuterium/tritium separation. Our object is to find the simplest and most

\footnotetext{
Received September 7, 1979. Correspondence concerning this article should be addessed to $\mathrm{K}$. Takeuchi.
}

useful expressions in kinetics that can be used for scale-up purposes based on the minimum number of experimental results.

For this goal, the reaction $\mathrm{BCl}_{3}+\mathrm{H}_{2} \mathrm{~S}$ is adopted as a model reaction, since $\mathrm{BCl}_{3}$ has isotopically selective absorption peaks in the wavelength range of highly efficient $\mathrm{CO}_{2}$ lasers.

\section{Experimental}

A schematic diagram of experimental apparatus is shown in Fig. 1. A transversely excited atmospheric pressure (T.E.A.) $\mathrm{CO}_{2}$ laser (Lumonics 103-2) was operated with gas mixing ratio of 0.91:0.09:0.00 for $\mathrm{He}: \mathrm{CO}_{2}: \mathrm{N}_{2}$. The laser can emit maximum $1.4 \mathrm{~J}$ per pulse at a repetition rate of $0.7 \mathrm{~Hz}$. Nitrogen was not used as laser gas, to avoid possible thermal scrambling caused by the tail of the pulse such as reported by Freund $^{3 y}$. The original beam pattern was roughly rectangular, $3 \mathrm{~cm} \times 3.5 \mathrm{~cm}$. Teflon irises were used to eliminate the inhomogeneous portion of the beam. Then the beam was focussed using a KRS-5 lens $(\mathrm{f}=30 \mathrm{~cm})$ at the center of the cross-shaped cell, which was $30 \mathrm{~cm}$ long in irradiation direction and $5 \mathrm{~cm}$ long for IR spectroscopic analysis. The reaction cell was made of Pyrex with four $\mathrm{KBr}$ windows $(35 \phi \times 5 \mathrm{~mm})$. For all runs, concentrations of ${ }^{11} \mathrm{BCl}_{3}$ and ${ }^{10} \mathrm{BCl}_{3}$ were measured by a double-beam IR spectrophotometer (JASCO A102) using absorption peaks at $956 \mathrm{~cm}^{-1}$ and $995 \mathrm{~cm}^{-1}$, respectively. Pulse energy measurements were made before and after passage through the cell by a disk calorimeter (Scientech 361). The reaction cells were dried by heating for 48 hours under vacuum before use to avoid non-selective thermal 


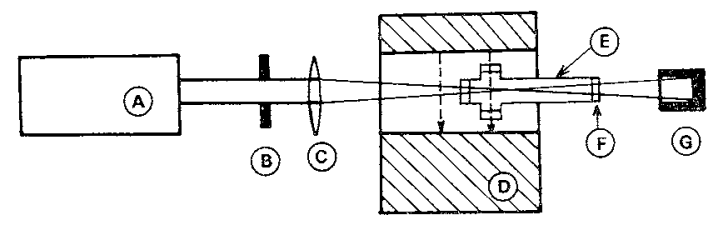

(A) $\mathrm{CO}_{2}$ T.E.A. laser (Lumonics 103-2)

(B) iris (C) lens (KRS-5, $\mathrm{f}=30 \mathrm{~cm}$ )

(D) IR spectrophotometer (JASCO A-102)

(B) gas cell (E) $\mathrm{KBr}$ window

(C) disk calorimeter (Scientech 361)

Fig. 1 Schematic diagram of experimental apparatus

hydrolysis of boron trichloride. $\mathrm{BCl}_{3}$ gas containing naturally abundant $20 \%{ }^{10} \mathrm{BCl}_{3}$ and $80 \%{ }^{11} \mathrm{BCl}_{3}$ of $99.9 \%$ purity and $\mathrm{H}_{2} \mathrm{~S}$ gas of $99 \%$ purity were supplied by Matheson and then vacuum-distilled for further purification.

The laser line was tuned at $\mathrm{P}(20)$ line at $944.2 \mathrm{~cm}^{-1}$ so that it might be in resonance with ${ }^{11} \mathrm{BCl}_{3} \nu_{3}$ asymmetric stretching mode. Initial pressures for $\mathrm{BCl}_{3}$ and $\mathrm{H}_{2} \mathrm{~S}$ were $0.27 \mathrm{kPa}$ and $1.33 \mathrm{kPa}$, respectively.

\section{Results and Discussion}

Figure 2 shows a typical example of IR spectra before and after irradiation. Resonant ${ }^{11} \mathrm{BCl}_{3}$ is more reacted than non-resonant ${ }^{10} \mathrm{BCl}_{3}$.

Figure 3 shows that the concentration changes for ${ }^{11} \mathrm{BCl}_{3}$ and ${ }^{10} \mathrm{BCl}_{3}$ obey pseudo-first order kinetics as given by Eq. (1) since the plot of $-\ln (1-X)$ vs. $t$ is linear, where $X$ is the fractional conversion of each isotopic compound and $t$ is the number of pulses.

$$
\begin{aligned}
& 1-X_{A}=\exp \left(-d_{A} t\right) \\
& 1-X_{B}=\exp \left(-d_{B} t\right)
\end{aligned}
$$

Hydrogen sulfide used as the acceptor is always in excess. The slopes $d_{A}$ and $d_{B}$ give the overall reaction rate constants, and the ratio of the two slopes in Fig. 2 is defined as the selectivity $S$.

In infrared laser isotope separation, the relation corresponding to temperature dependence of thermal reaction rate constants is the pulse energy dependence of $d_{A}$ and $d_{B}$. We shall discuss this subject, as most physicists do, by utilizing a power law expression such as

$$
d_{A}=A^{\prime} E_{0}^{m}
$$

Figure 4 shows the pulse energy dependence of $d_{A}$ and $d_{B}$ based on Eq. (2). While $d_{A}$ is proportional to $E_{0}^{0.90}, d_{B}$ is proportional to $E_{0}^{0.68}$, indicating that selectivity increases with $E_{0}$.

Dependence of the reaction rate constants on incident pulse energy $E_{0}$, fluence $\Phi$ and beam intensity $I$ has been extensively studied for other molecules such as $\mathrm{SF}_{6}$. The values for $m$ in the relation $d_{A} \propto \Phi^{m}$ range from 1.01 to 1.96 and 1.5 to 2.77 in the relation $d_{A} \propto E_{0}^{m}$ for $\mathrm{SF}_{6}^{1,2,4,7)}$. Since the experimental error

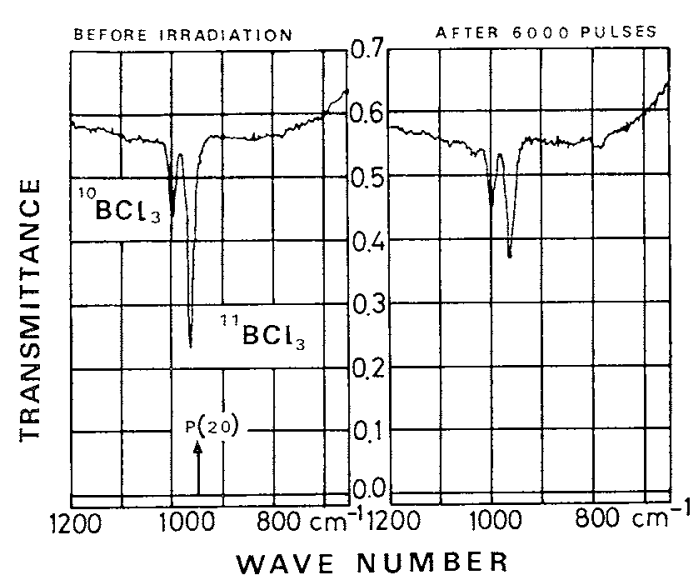

Fig. 2 Examples of typical IR spectra of $\mathbf{B C I}_{3}$ $(0.27 \mathrm{kPa})$ before irradiation (left) and after irradiation of 6000 pulses (right) at $944.2 \mathrm{~cm}^{-1}$

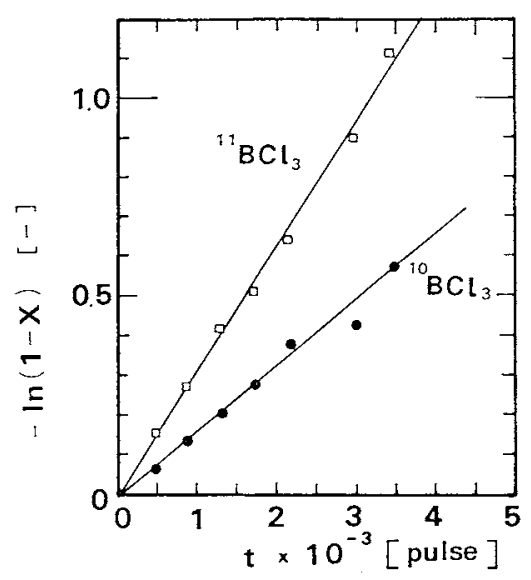

Fig. 3 Plot of fractional unconversion $(1-X)=$ $N / N_{0}$ vs. pulse number $t$ for resonant ${ }^{11} \mathrm{BCl}_{3}$ and non-resonant ${ }^{10} \mathrm{BCl}_{3}$

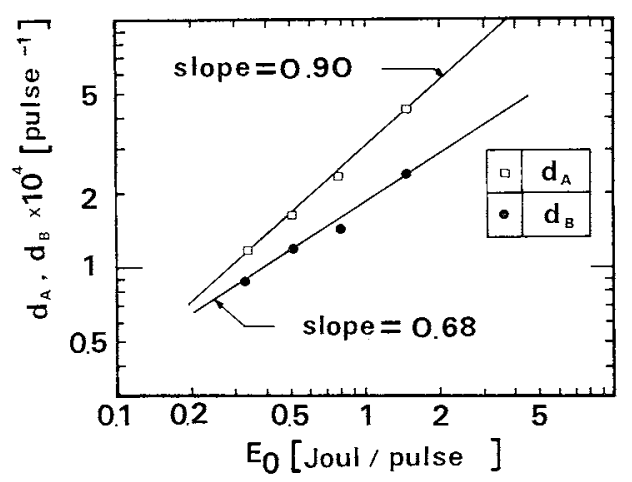

Fig. 4 Dependence of resonant reaction rate constant $d_{A}$ and non-resonant reaction rate constant $d_{B}$ on incident pulse energy $E_{0}$

associated with the determination of $m$ is estimated to be $\pm 15 \%$, the interpretation of linear dependence of $d_{A}$ on $E_{0}\left(d_{A} \propto E_{0}^{1}\right)$ shown by Gower et al ${ }^{4)}$ for multiphoton dissociation of $\mathrm{SF}_{6}$ can be applied to this case. That is, the local reaction rate constant $k$ in a small segment of the irradiated volume can be related linear- 


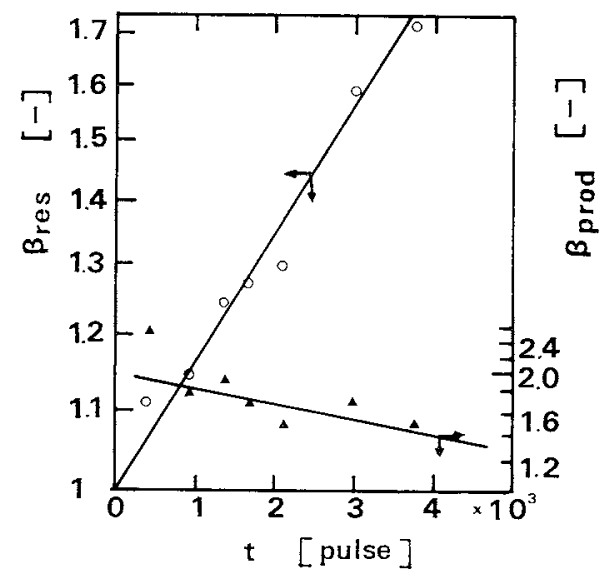

Fig. 5 Experimentally obtained enrichment factor for the unreacted $\beta_{\text {res }}$ and that for the product $\beta_{\text {prod }}$ as function of pulse number $t$ in comparision with theory (solid lines)

ly to spatially and chronologically variable beam intensity $I\left(k \propto I^{1}\right)$. Therefore the pulse energy dependence for a resonant molecule is expected to be independent of irradiation geometry.

On the other hand, that for a non-resonant substance is more complex since $d_{B}$ is the result of spatial and chronological averaging of the non-linear dependence on $I$.

This is due to the fact that we start from a crude parallel reaction model such as shown in scheme (I) rather than a more realistic model such as scheme (II) as shown below.

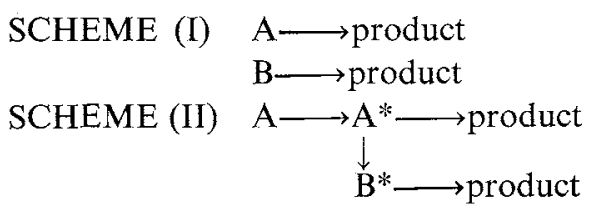

Without further investigation of the kinetics of $\mathrm{v}-\mathrm{v}$ excitation transfer $\mathrm{A}^{*}+\mathrm{B} \rightarrow \mathrm{A}+\mathrm{B}^{*}$, the pulse energy dependence of $d_{B}$ cannot be fully understood.

Nevertheless, when Eqs. (1a) and (1b) hold, the enrichment factors $\beta_{\text {res }}$ for the unreacted and $\beta_{\text {prod }}$ for the product can be written as

$$
\begin{aligned}
& \beta_{\mathrm{res}} \equiv \frac{\left(N_{B} / N_{B O}\right)}{\left(N_{A} / N_{A O}\right)}=\exp \left(\frac{S-1}{S} d_{A} t\right) \\
& \beta_{\mathrm{prod}} \equiv \frac{\left(N_{A O}-N_{A}\right) / N_{A O}}{\left(N_{B O}-N_{B}\right) / N_{B O}}=\frac{1-\exp \left(-d_{A} t\right)}{1-\exp \left(-\bar{d}_{B} t\right)}
\end{aligned}
$$

From Eq. (3), it is easily understood that $\beta_{\text {res }}$ can be increased exponentially as $t$ is increased. But for the sake of realistic isotope separation where the abundance of the desired isotope is low, $\beta_{\text {prod }}$ is more important. Simple calculation shows that $\beta_{\text {prod }}$ decreases monotonically as $t$ increases. The maximum value for $\beta_{\text {prod }}$ is equal to $S$ at $t=0$ where $S=d_{A} / d_{B}$.

The same data in Fig. 3 is reproduced in Fig. 5 with $\beta_{\text {res }}$ and $\beta_{\text {prod }}$ to illustrate the process of batch isotope enrichment as given by Eqs. (3) and (4). This also illustrates the importance of the finding of the phenomenological pseudo-first order expressions such as Eqs. (1a) and (1b) since it leads to such simple expressions for $\beta_{\text {res }}$ and $\beta_{\text {prod }}$ as in Eqs. (3) and (4), though intrinsic mechanisms for multiphoton excitation and chemical reaction accompanied by resonant excitation transfer among many vibrational levels causing scrambling can be quite complex.

\section{Conclusion}

The kinetic model for infrared laser isotope separation is presented to elucidate the results of batchwise experiments with a series of pulsed irradiation. Overall kinetics was found to obey the pseudo-first order parallel reaction scheme for resonant ${ }^{11} \mathrm{BCl}_{3}$ and nonresonant ${ }^{10} \mathrm{BCl}_{3}$.

This enables us to express the enrichment factors for the unreacted and the product in simple fashion as functions of the resonant reaction rate constant $d_{A}$ and the selectivity $S$.

\section{Acknowledgment}

The authors are grateful to Professor Susumu Namba and his co-workers in the Semiconductor Laboratory of the Institute of Physical and Chemical Research for their kind permission for our use of the $\mathrm{CO}_{2}$ T.E.A. laser and numerous valuable sugges-

\begin{tabular}{|c|c|c|}
\hline \multicolumn{3}{|c|}{ Nomenclature } \\
\hline$d_{A}$ & $\begin{aligned}= & \text { overall reaction rate constant for } \\
& \text { resonant molecule } \mathrm{A}\end{aligned}$ & {$[-]$} \\
\hline$d_{B}$ & $\begin{aligned}= & \text { overall reaction rate constant for } \\
& \text { non-resonant molecule } \mathrm{B}\end{aligned}$ & {$[-]$} \\
\hline$E_{0}$ & $=$ incident pulse energy & {$[\mathrm{J}]$} \\
\hline$I$ & $=$ beam intensity & {$\left[\mathrm{W} / \mathrm{cm}^{2}\right]$} \\
\hline$k$ & $=$ local reaction rate constant & {$\left[\mathrm{s}^{-1}\right]$} \\
\hline$N_{A}$ & $=$ concentration of $\mathrm{A}$ after irradiation & {$\left[\mathrm{mol} / \mathrm{cm}^{3}\right]$} \\
\hline$N_{B}$ & $=$ concentration of $\mathrm{B}$ after irradiation & {$\left[\mathrm{mol} / \mathrm{cm}^{3}\right]$} \\
\hline$N_{A O}$ & $=$ concentration of $\mathrm{A}$ before irradiation $[\mathrm{n}$ & {$\left[\mathrm{mol} / \mathrm{cm}^{3}\right]$} \\
\hline$N_{B O}$ & $=$ concentration of $\mathrm{B}$ before irradiation $[\mathrm{r}$ & {$\left[\mathrm{mol} / \mathrm{cm}^{3}\right]$} \\
\hline$S$ & $=d_{A} / d_{B}=$ selectivity & {$[-]$} \\
\hline$\beta_{\text {res }}$ & $\begin{aligned}= & \text { enrichment factor for unreacted gas as } \\
& \text { defined by Eq. (3) }\end{aligned}$ & {$[-]$} \\
\hline$\beta_{\text {prod }}$ & $\begin{aligned}= & \text { enrichment factor for product as defined } \\
& \text { by Eq. (4) }\end{aligned}$ & {$[-]$} \\
\hline$\Phi$ & $=$ fluence & {$\left[\mathrm{J} / \mathrm{cm}^{2}\right]$} \\
\hline
\end{tabular}
tions.

\section{Literature Cited}

1) Ambartzumian, R. V. et al.: Sov. Phys. JETP, 42, 993 (1975).

2) Fuss, W. and T. P. Cotter: Appl. Phys., 12, 265 (1977).

3) Freund, S. M. and J. J. Ritter: Chem. Phys., Lett., 32, 255 (1975).

4) Gower, M. C. et al.: Opt. Comm., 20, 123 (1977).

5) Kimel, S. and S. Speiser: Chem. Review, 77, 437 (1977).

6) Letokhov, V. S.: Physics Today, May, 23 (1977).

7) Lyman, J. L. et al.: J. Chem. Phys., 67, 4545 (1977).

8) Moore, C. B., "Chemical and Biochemical Applications of Lasers", vol. III, p. 122, Academic Press (1977). 